\title{
Development of Design Ideas: Fusion of Culture- The Silk Road Dream through Fashion Art
}

\author{
S M Minhus ${ }^{1}$ Liang Huie ${ }^{1,2^{*}}$ \\ 1. College of Textiles \& Clothing, Jiangnan University, No. 1800 Lihu Avenue, Wuxi 214122, China \\ 2. Jiangsu research center for Intangible Cultural Heritage, Jiangnan University, No. 1800 Lihu Avenue, \\ Wuxi 214122, China \\ * E-mail of the corresponding author: lianghe@jiangnan.edu.cn
}

This research is financed by "The Major Projects of Philosophy and Social Sciences Research in Jiangsu Universities (2019SJZDA021).”

\begin{abstract}
How to execute the ideas of designer's mind through a theme of design according to fashion scene into factual mockups with the consumers' acceptance is the prime object in design sector. The main intention of this study is to develop the design ideas according to specific theme, process to carry out those design into wearable form, fulfilment of designer's achievement and research values of design theme. Author developed a design collection as a designer for a renowned fashion design competition hold in Shanghai, with a given competition concept on the 'Silk Road' and the principles of innovation. To execute the design theme towards the final steps of achievements designer used different process of design accordingly and this study will discuss step by step developments. In this design idea there will have a discussion of Silk Road dream in terms of fashion art to realize the actuality of design according to theme. From this study one can realize the relation between theme research and design ideas as well as the systematic method of design development as a designer, and will help the design students as a self-learning guide to understand about participating fashion design competition. The given experiment of design process will be considered as an example to illustrate the focus point of this research.
\end{abstract}

Keywords: Design development, Silk Road, Fusion of culture, Fashion art, Achievement

DOI: $10.7176 / \mathrm{ADS} / 79-10$

Publication date: December $31^{\text {st }} 2019$

\section{Introduction}

A variety of looks can be brought together to illustrate a bigger idea for inspiration and mix itself as an extension of the concept that inspired each element of the collection to begin with. Many choices are involved in designing a single garment, creating corresponding pieces to put together an outfit, and then doing that numerous times until you have all the ingredients necessary to tell your fashion story as a collection (Delong, 1998). Intellectual practices are designed to serve as catalyzers for progressing creativity. How designers use the sources of inspiration to create designs for fashion depends on the constraints of the problem. Pursuing other designs and main motifs on specific characters ascertain the sources (Volpintesta, 2014). Designers creating color or structure of patterns often refer to the objects and images that they have collected from the source, and methodically search through different ways to find the sources of inspiration from where something they can take into design form that will give the strength for particular emergent of perceptual characteristics (Eckert \& Stacey, 2000). Fashion is an intention of change and emulation, the factor of fashion changes relies on socio-psychological, economical, ideological and technological aspect (Simmel, 1914).

It's imperative to consider the life of a garment when designing it, such as how the garment will hold up over time, through wear, cleaning, and steaming. This can make the difference between having an object that is a keepsake and one that is relegated to the dustbin. In some cases, it is the patina that develops during the aging process that adds to its desirability. In others, the value comes from the item's ability to retain as good as new appearance over time (Watkins, 1988). Fashion influences come from many different sources, including sports, clubs, social and economic class, and different cultures. It's up to the designer to translate and adopt these influences to fit into the mainstream. A fashion designer may be tempted to avoid steps in the creative process to meet deadlines or simply reap the rewards a little sooner (Solomon, 1985). Whether it's in sketching, pattern making, or sewing, by passing steps could undermine the final outcome. In addition to getting it right the first time, each and every phase of 
preparation provides an opportunity for inspiration (Archer, 1974). The rules don't necessarily change, but the ones you apply, as well as how, when, and where you apply them, is a creative act in itself. The connection between the mind's eye and the hands of the designer is easily taken for granted. This link must be reinforced through conscious exercise and exploration (Kosslyn, 1980). If the communication between the two is fluid, a designer's dexterity in executing ideas becomes effortless and, after a time, second nature. Building strong bonds requires equal parts artist, architect, and construction worker. It's easy to play to your strengths, but a good designer will have a clear comprehension of cause and effect in every area. A designer should be able to navigate between visual mode where the imagination and aesthetics are paramount, the blueprint phase that documents and communicates how each design will be executed, and building something that respects and reflects the original vision and intent. The more direct the path between the designer's imagination and the realities of producing it, the better the work (Aspelund, 2010).

One of the most important stages in the design process is self-correction. There may be a sense of something being off, but it's difficult to pinpoint the problem. To do this objectively, the piece needs to be taken out of context. There are several ways to check the work. While rendering a two-dimensional representation of a design, turning the sketch upside down so that it can be seen as an abstract object helps to make imbalances obvious. A version of a sketch on tracing paper can be folded in half $\mathrm{d}$ own the figure's center to avoid unwanted distortions (Lawson, 2006). While fashion makers should be at the controls when developing the clothes, it is the consumers who will decide how loud they dare to be. Designers are advised to keep in mind that psychology is always in play when pushing the envelope, so they should be ready to address any issues with the consumer (Cross, 2001). This study is to aim on the concept of design creation principle with a specific theme that will be analyzed by proper discussion step by step until the achievement comes out.

\section{Design concept}

The first step to create a design is to conceive of the ideas or concepts for the collection, which will convey a clearcut fundamental theme or narrative. This is done by conducting research, and drawing upon inspiration. Fashion history is the next best thing to a time machine for the fashion designer (Mbonu, 2014). Have the good concept of fashion rotation from the history, culture to present and transformation into modern design as the inspiration. Designers, like artists, are often courting their muses for inspiration (Christiaans, 1992). Even though the desire to fit in is strong, the idea of individuality allows a person to feel special. Design is as much about what you add to the mix as what you elect not to add. The point is that regard less of whether you like something you don't understand you can't dismiss it, because it has grabbed your attention. It can be appreciated merely for having been able to shake things up and penetrate established standards of beauty far enough to challenge you. A truly creative mind is one that builds a foundation with the left brain so that the right brain can make giant leaps of fancy (Oxman, 2002). It's easy to create a focus on natural tendency what the brain has and have the idea about what to do or not. Strengthening those shortcomings is a key to success. Lefties are analytical, technical, critical, and logical. They need to stretch to tap into the part of their brain that allows them to be more intuitive, imaginative, and innovative. Simultaneously entertaining opposing needs and desires can be a tough thing to contain in your brain. In order to overcome natural tendencies that lean to one side or the other, a designer needs to move the process outside of her head. There are several ways to map out a successful creative strategy that allows the designer to see, sort, and shuffle everything involved. 


\section{Methodology}

Table 1: Method to describe this research for the development of design ideas

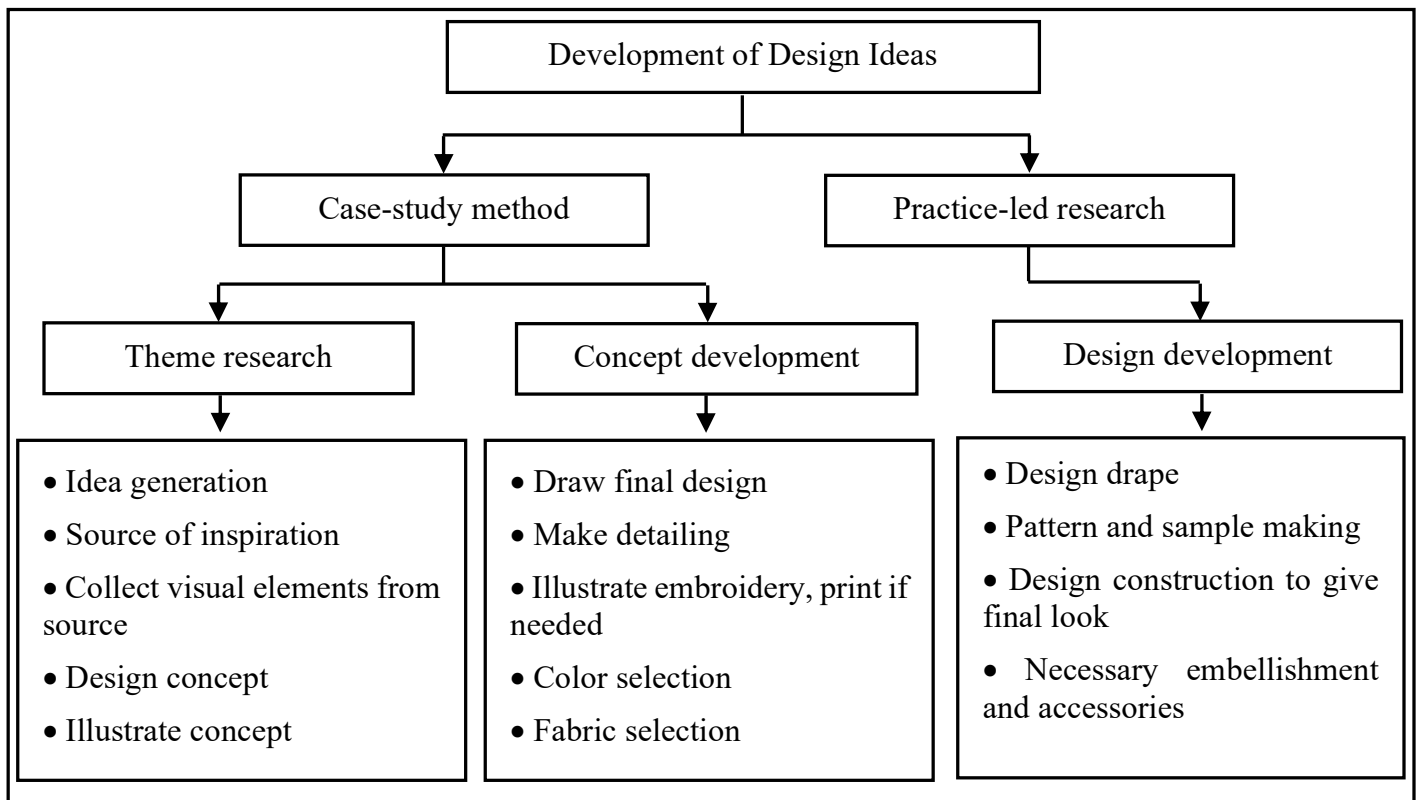

Methods of process depends on way of design work that varies designers to designers. Sometimes process can be same but thoughts are different. In this study designer applied his own concept to complete the design according to theme for a design competition. Case-study method and Practice-led research applied for the development of design ideas.

\section{Process and Discussion}

\subsection{Analyze the source of inspiration}

The specific decisions that a designer makes-putting emphasis on what she sees as important, will ultimately set her apart from other designers and their collections. This process is just as important as the garments themselves, because it places the designer's vision in a context of her own creation.

Silk Road related with silk originated from China spread all over world with their important elements, product, techniques, art and that brining the great influence in the field of economic, social and cultural prosperity among the countries and regions along with Silk Road. Silk Road serves as a symbol of cooperation and exchange among different cultures and nations by the contribution to consolidate public and social basis of 'One Belt and One Road' initiative (Feng, 2015). The concept of this initiative is that the world become more colorful through the cultural exchange and diversified through mutual perception. The precious cultural relics, one by one, have vividly reflected the spirit of the Silk Road of peaceful cooperation, openness and inclusiveness, mutual study and mutual benefits. In this design collection designer makes the connection among the nations under Silk Road economic belt and make the concept through 'Fusion of Culture'.

\subsection{Illustrate concept into design form}

Bangladesh is the nation under Silk Road economic belt and designer took some elements from this country's culture as an inspiration to merge with and to create a design concept with modern design cutline, fusion with cultural influence as a feeling of estheticism. Design that influenced by cultural norms, is generally followed by the continuously changing trends in the society. In this design concept designer used the techniques of Bangladeshi traditional hand embroidery and cultural color influence that makes the ideas to feel elegance. Finding the right balance between different shapes is an important factor, whether the designer wants the complete look to have a reserved silhouette or one with dramatic flair. From the sources designer collected information and images of color concept, traditional elements to make an inspirational board that gives the ideas for illustration balanced with theme and design concept. 
Designer sketches more sample designs for the collection according to theme from the inspiration board and those illustrations have the influence of both cultural and modern cutline (Figure 1). During this design experiment some questions arises in designers to make clear about the inspiration are: a) Which elements can be used to modernized the design form cultural ethics? b) What is the relation between competition theme and designer's inspiration? c) How to change the sketching to keep theme concept? Finding the right balance between different shapes is an important factor, whether the designer wants the complete look to have a reserved silhouette or one with dramatic flair.

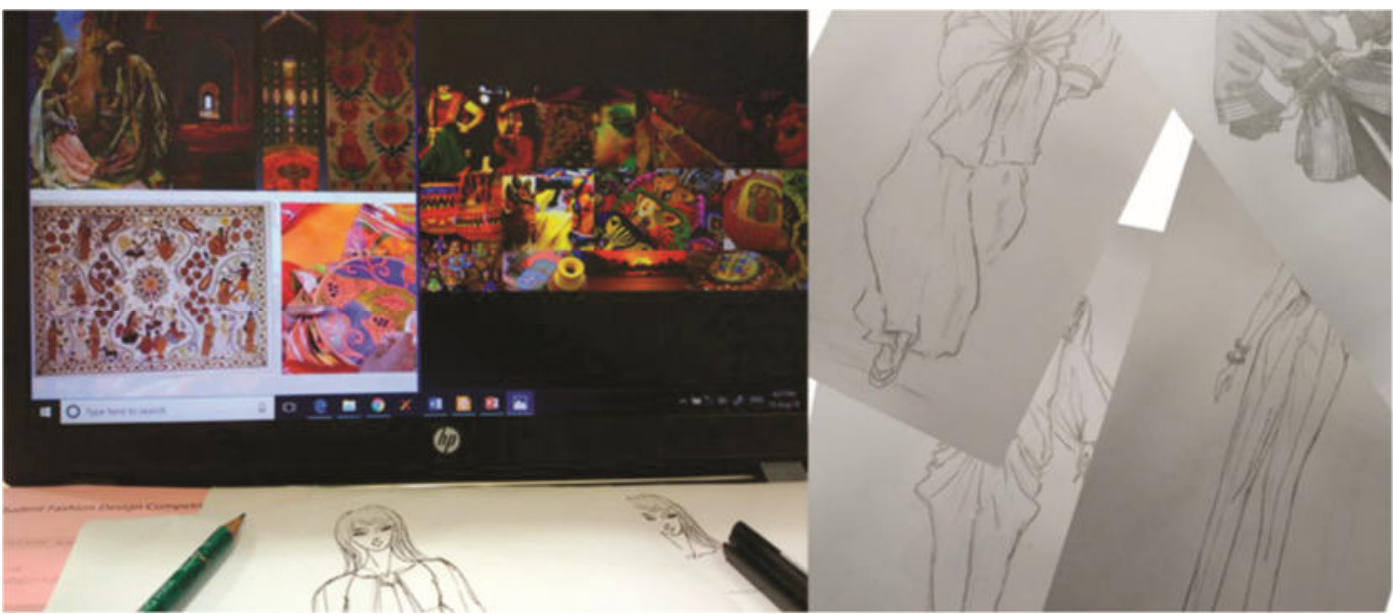

Figure 1. Images captured during design experiment and sample sketches drawn from inspiration.

\subsection{Concept development}

Nothing in fashion is totally new; it is a cycle with reinvention at its core. The ability to innovate or to create the new, is developed through strong research application, which is, therefore, an essential skill for a designer. Whether engaging with technological advances in fabric or reacting to a current political mood, designers are at the forefront of creative endeavors (Lee \& Jirousek, 2015). To develop the concept from the inspiration need continue the processes step by step. At this point, all research and inspiration is gathered, and initial sketches and illustrations are created by hand. Three sets of sketches selected for final design from all sample sketches, after that transferred the hand sketches into digital form by using Coraldraw and Photoshop design softwares with detailing (Figure 2).

In figure- 2 from the first design we can see 3 parts and the upper part don't have any sleeves but have arm holes from both sides with the hand embroidery on left side shoulder's front part. Inner body front both sides have symmetric design with all over hand embroidery on red cotton fabric and pleats, opening buttons. Trouser have weave technique, hand embroidery and one side open skirts binded with waist band as well as decorated with beads work. The second design have 3 parts with sleeveless upper coat, embroidery on the left shoulder and inner part front side have symmetric design; one side have full hand embroidery design with waist belt and loose trouser with weave technique on the bottom and hand embroidery. In 3rd design have 4 parts with hand embroidery, broken shoulder sleeves, chocker, long over coat, long sleeves, waist belt and special loose pleated trouser. Cotton and cotton-polyester blended fabric was selected for this design with 3 major color such as red, green and dark yellow according to design theme and inspiration concept. Mixing drastically different colors can punch up a look. Blending more harmonious shades will result in a gentler touch. At either end of the spectrum or anywhere in between, color should always allude to the impact the designer wishes to have on his audience. In this divergent and expansive first stage, primary, secondary, color, fabric and market research is undertaken, giving a wellinformed position from which can develop concept with a deeper level of understanding and subsequent application. 

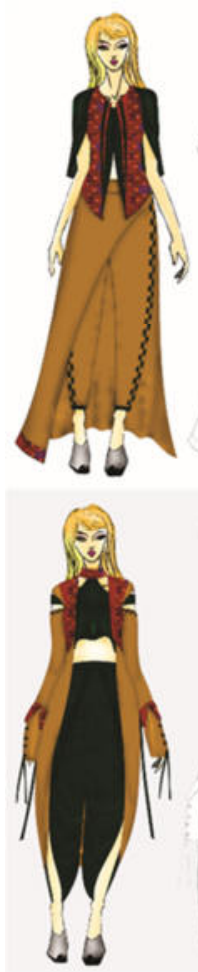
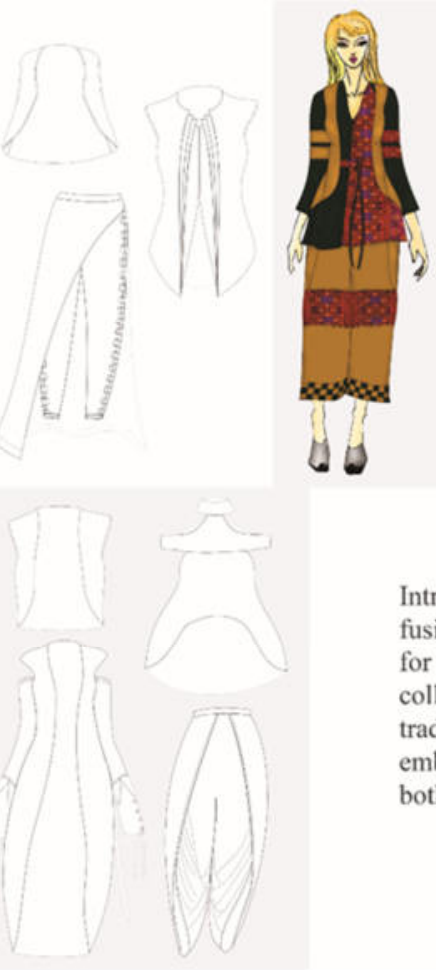

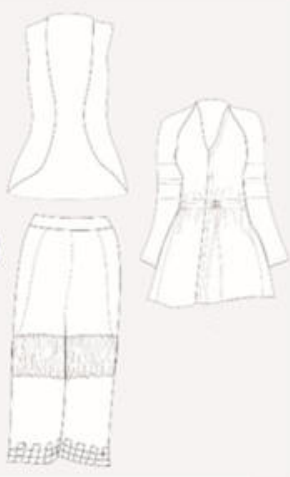

\section{Fabric Sample}

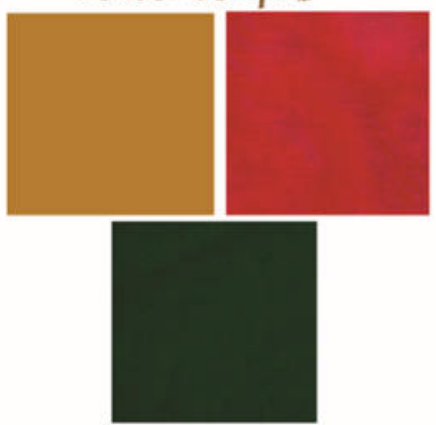

Fusion of Culture

Introducing a new design collection with the expression fusion of culture and the concept of contemporary design for ready to wear. Following the fashion trend this design collection has special making technique with Bangladeshi traditional kantha embroidery pattern. Those hand made embroidery used to stublish cultural exchange between both cultures in costume as well as fashion elements.

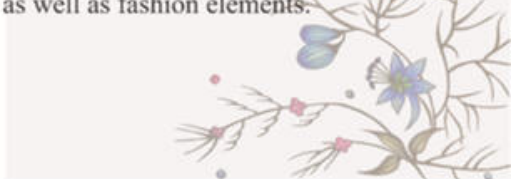

Figure 2. Final design for collection with detailing, color and fabric concept as well as inspiration explanation.

\subsection{Design development}

Fashion is an appearance of sculpture. Amazingly, it works with a medium weight (fabric) that is basically twodimensional, to create three-dimensional silhouettes and shapes, whether on the garment's surface, in the shaping of its components, and/or in its overall appearance (Lurie, 1981). In the atelier, fabric is either cut flat by instinct, with flat patterns, or draped on a dress form or model to create the patterns for reproduction and there is no complete way or many approaches. Individual pattern pieces that come out of the creation process are a set of twodimensional shapes that, joined together, build the three-dimensional one. The basic fitted pattern shapes are called slopers: a basic sleeve, bodice, shift dress, princess-line dress, jacket, pant, and skirt pattern. From these basic fitted pieces, using a traditional dressmaker's approach, new pattern shapes can be created, controlling the actual shaping of each seam or panel, and thus, the shape of the finished garment. Pattern shapes can be combined to create new shapes.
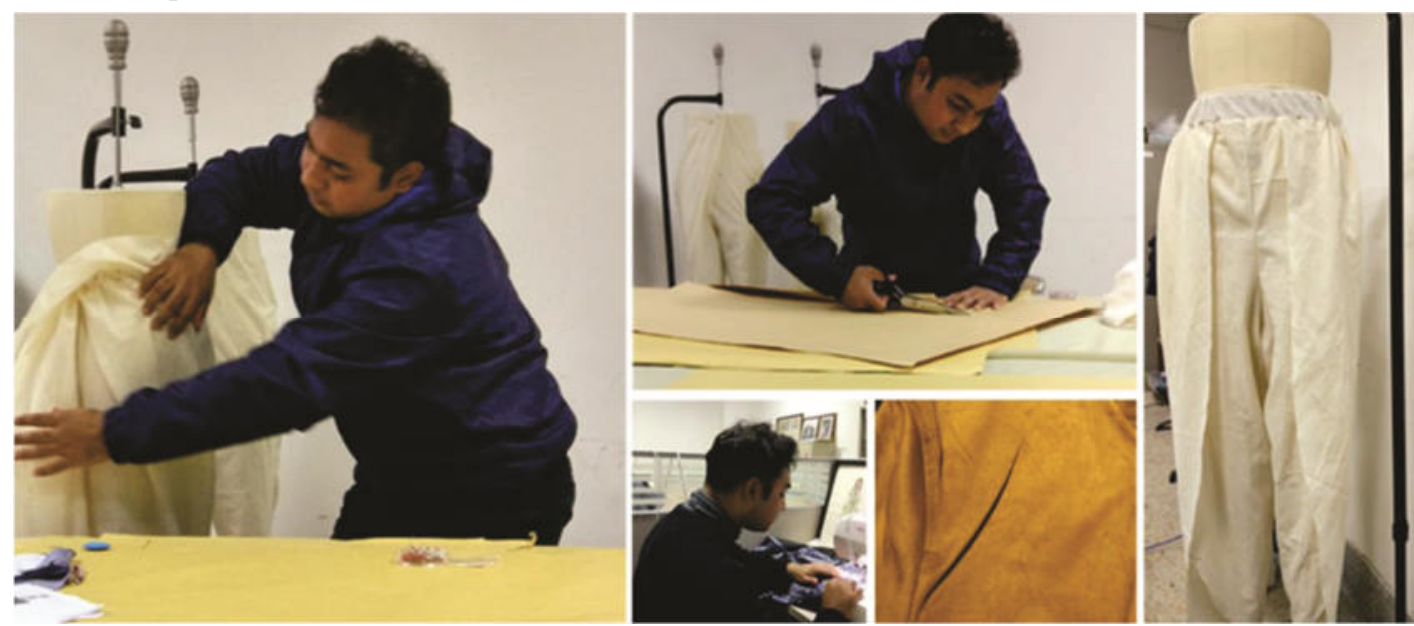

Figure 3. Images captured during step by step designer's (own) design developed process in studio. 
Any image that uses only one weight of line will call the eye to every line at the same time, but also have a spatially flattening effect. This can be desirable too, for certain stylistic applications, so experience and awareness are important. From the detailed design the patterns are taken from draping, after that make correction according to measurement that was given (Figure 3). A garment's unique silhouette personality takes on a life of its own, whether on a human, a hanger, or a display table (Pipes, 2003). Fashion begins with a body. We wrap it in fabric, enclose it in a garment, and get instant impact. A garment's size and the character of its shape are registered at a glance. After conforming the exact pattern and accurate fittings of sample draft designer started to make final face before that hand embroidery on red fabric was done that was overall fabric embroidery.

A garment is cut, fit, and finished. Embellishment denotes a last step, a finishing touch, an extra, yet not without prior consideration. Since the beginning of history, decoration comes after the essential step of creating the base garment except where decorative adornments, and not garments, were the only form of body decoration. In fashion, a base garment may exist only for the purpose of carrying the ornament, or inversely an ornament is applied to a finished garment, calling attention to itself as it lures the eye, then settling into the overall look (Sproles \& Burns, 1994). Embellishment is the punctuation mark of fashion design like the icing on the cake. Many embellishments walk a line between jewelry and garment. Jewelry can add interest or break up the symmetry of a garment and can be used interchangeably, depending on the mood or occasion, or even combine with different looks for different effects. Embellishments, however, carry a much higher level of commitment, staying with the garment, becoming an intrinsic part of the design, and so deserve careful consideration. The creativity in embellishment becomes the designer's choice and the wearer's agreement to carry. Prints, patterns, and textures are the more minute carriers of shapes, but when used this way, shape remains two-dimensional. On the other hand, embroidery, beads work, weaving techniques are remaining three-dimensional shapes.
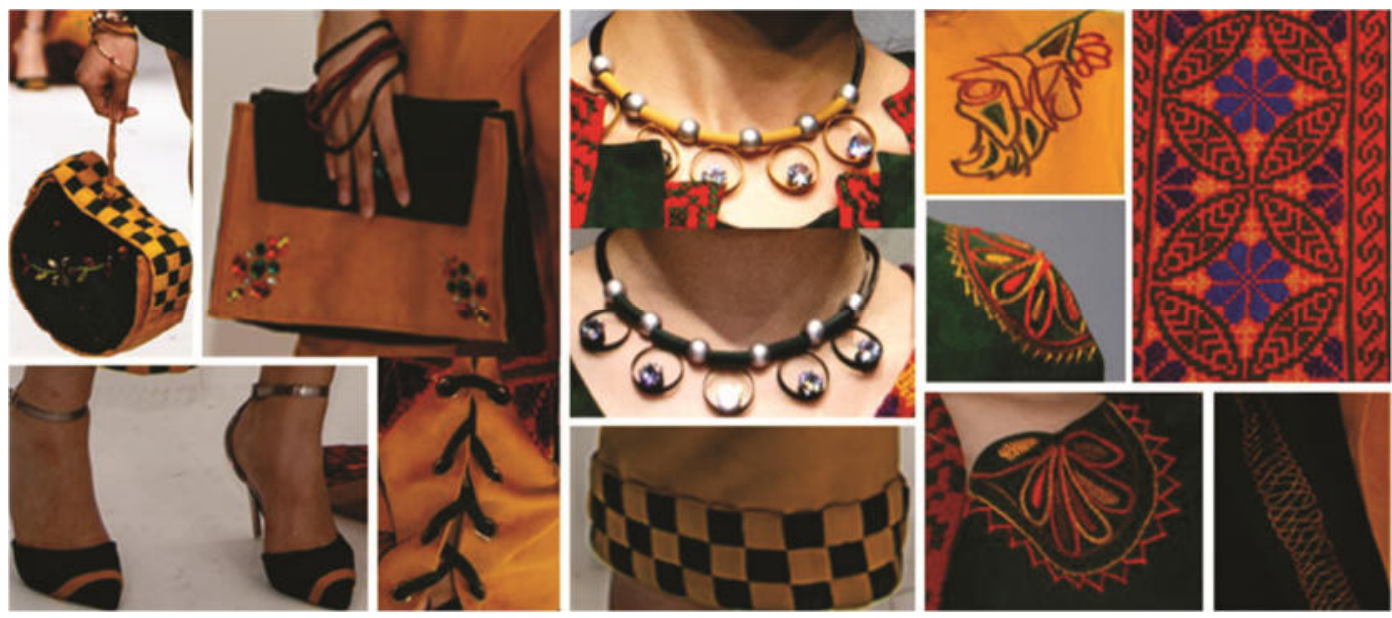

Figure 4. Images of collection's accessories, shoes, bags, ornaments, embroidery details.

Design development was done with step by step making process with details technique and sewing by the designer own. After completing sewing floral pattern hand embroidery and some embroideries was done on the different edges of the final garments before ironing. Fashion silhouette is never defined by garment alone - the hairstyle, body, shoes, mix of garment pieces, and accessories all contribute greatly to the final shape and effect, and the story becomes more complex and new looks are created as shapes play off one another. For the collection Bags, shoes, jewelries were prepared according to theme and balanced with collection that makes the appearance of estheticism (Figure 4). 


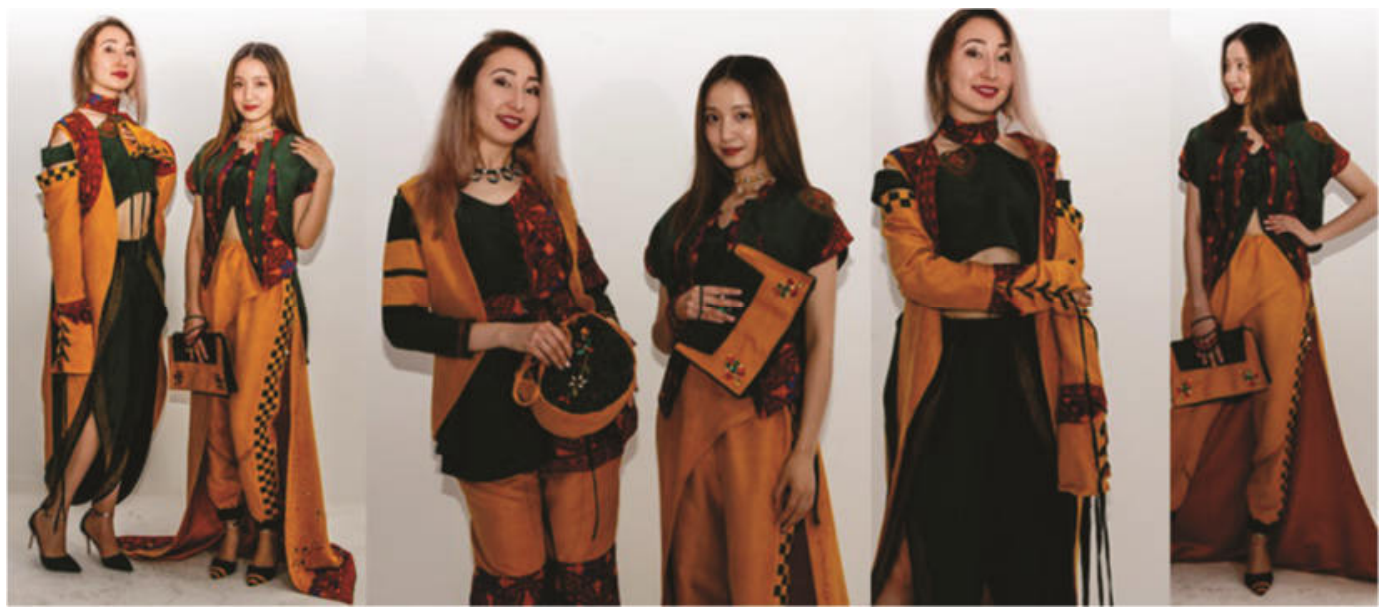

Figure 5. Images of dress fitness checking and photoshoot.

Imagination of a real looks from pictorial view is different from the final look on models' body or wearer body (Davis, 1996). Tuning in to silhouette in favor of details for a moment gives the designer, illustrator, or wearer precise control over the aesthetics of shape. After completing all the decorations in garments to give final look designer prepare the collection for checking the fittings and photoshoot to have a real experience about designs (Figure 5).

Design competition and fashion show gives the opportunity to realize designer's works and it is the indicator of skill and repletion in design as well as value of concept. Pictures are taken from different angles and focuses on detailing of the costumes as a part of design competition requirements. After that designer prepared the collection for fashion show during the competition (Figure 6) and make the proper styling and makeups for the models.

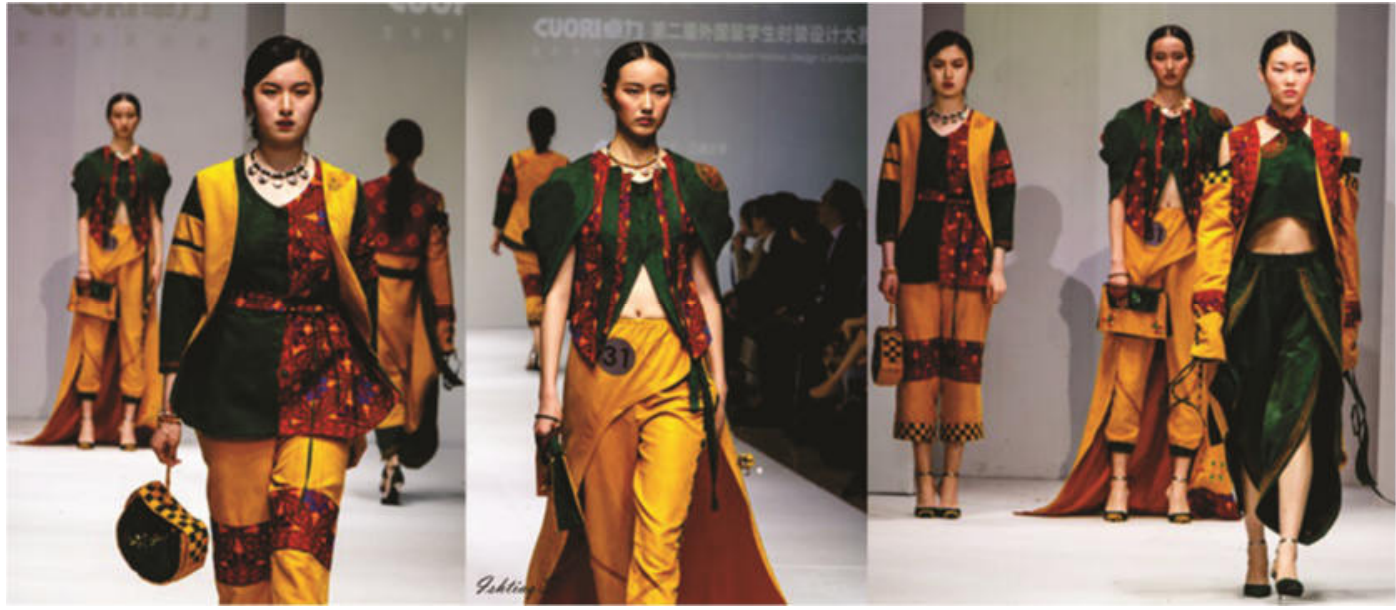

Figure 6. Picture captured during the fashion show of designer's collection in Shanghai.

\section{Analytical view}

Fashion research is a creative investigation that can yield ideas, which then inspire and contribute to the design process. The deeper of investigation, the more design opportunities it will provide - thorough research allows more links between the layers of research material to be made, simply because there is more material to work with (Bayazit, 2004). Superficial research, as the name suggests, just skims the surface; fewer links can be made, so it usually results in design ideas that have undergone insufficient development. Research should define the concept and the creative direction through a process of assimilation and editing. The concept of the study provides the real view to know about design competition collection, detailed designer's creative and experimental work, relation between design theme research and creative idea generation. 
A collection will often reflect the time in which it was created, whether through technological, color, or silhouette trends or visual content, although a collection will have a universal quality if it is made to last beyond trends. Most designers design and produce collections. Although one-of-a-kind and unique pieces can hold a higher value for their labor and uniqueness, pieces that are presented and created together reflect a particular complex design process involving functionality and cohesion that is engaging for the viewer, the buyer, and the designer. In this research discussed clearly about a collection from the design concept to final stage of design step by step that gave an idea about a design process, designer works for a collection and design competition. All these procedures are designer's own work that was done very sincerely to make a successful design collection according to theme and have a sense of fusion of culture with the feelings of estheticism. For design development case study method shows the way to bring out something creative from source of theme and practice-led research gave the ideas to present the creation into visual form with complete look.

\section{Achievement}

On April 26th, during 24th Shanghai Fashion week, the International student education management branch of Chinese higher education institute and 2018 fashion Shanghai Donghua University jointly organized "CUORI CUP" the second annual International student fashion design contest. Through the different stages of judgment before the final race, this design work "Fusion of Culture" became the first and won the "gold award prize" among the top 35 designers' work of 18 universities from 22 countries. This competition pays attention to the interaction and mutual learning of different cultures, and sets the stage for international students to display fashion design ideas. The theme of the competition is wide and creative, and it shows the fusion of "One Belt and One Road" aesthetic and multi-design culture.

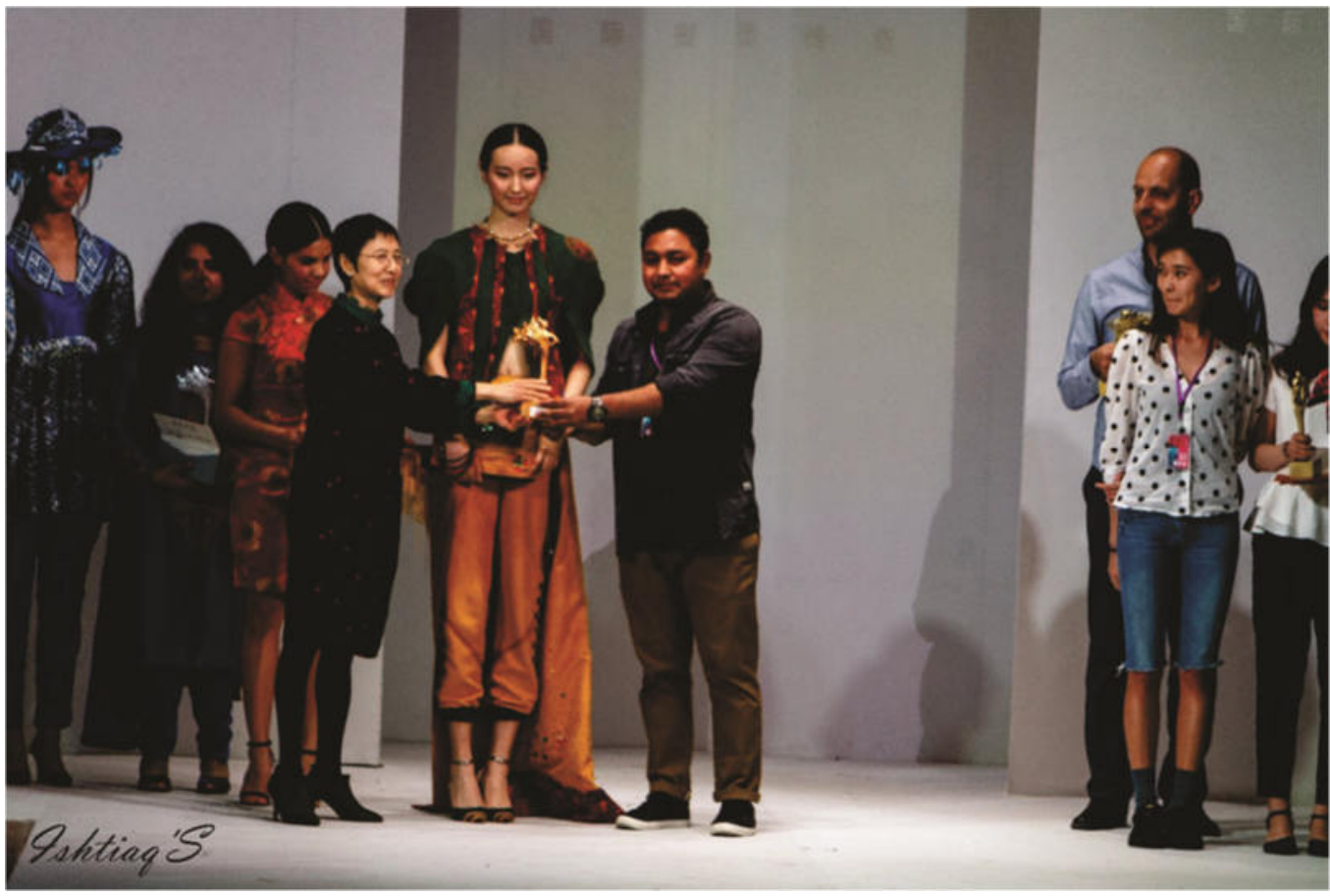

Figure 7. Image captured during award giving ceremony of "CUORI CUP- The 2nd International Student

Fashion Design Competition" and author (in the middle with model) taking gold award as first price for this collection.

\section{Conclusion}

Presenting clothing collections, depending on how they are worked out, can encourage or discourage the customer to pick up more than one piece. A collection of interchangeable and varied pieces will encourage consumers to gather and creatively mix the pieces with each other and their existing wardrobe, while a group of dresses or repeating colors and lengths might be too redundant to warrant purchasing more than one piece. A design collection usually addresses a season, a lifestyle, a specific group of fabrics for a specific price point around an idea or theme, for a target customer. The theme may be visual, conceptual, or color based. Collections offer options within a 
temporal theme and are usually produced in quantity with a set of fabrics and shapes selected for specific reason. A broad line or collection enables the designer to reach a wider audience with more options. A theme, a shape, an art movement, a new fabric manipulation, embroidery, color, motif, treatment, or construction technique may play across garments in a collection to make it cohesive. A group of textures, prints, a historical or cultural reference, exploration of a silhouette, or attempts to solve a specific design problem could also form the basis for a collection. One of the unique aspects of fashion design compared with other visual arts is that it comes to life on a moving, breathing, human form. This, to the designer or viewer, is a sublime aspect of the art. Fashion lives and moves in its peak moments. It expresses the soul of the wearer, envelops their body, and accompanies their every action. This is as three-dimensional as design gets! When fashion truly moves in the breeze, flowing around and behind the wearer, softness and drama come into play. So, the overall message from this study is to have the clear concept about design research, inspiration, concept, making process, final look of a collection, sincerity and passion to gain the achievement.

\section{References}

Archer, L. B. (1974) Design awareness and planned creativity in industry, illustrated edition. Ottawa: Department of Industry, Trade and Commerce and the Design Council of Great Britain.

Aspelund, K. (2010) The Design Process, $2^{\text {nd }}$ edition. New York: Fairchild Books.

Bayazit, N. (2004) Investigating Design: A Review of Forty Years of Design Research. Design Issues 20(1), 1629.

Christiaans (1992) Creativity in Design: The Role of Domain Knowledge in Designing. PhD Delft University of Technology.

Cross, N. (2001) Designerly ways of knowing: Design discipline versus design science. Design Issues, 17(3), 4955.

Davis, M. (1996) Visual design in dress $3^{\text {rd }}$ edition. Englewood Cliffs: Prentice-Hall.

Delong, M. R. (1998) The way we look: Dress and aesthetics $1^{\text {st }}$ edition. New York: Fairchild Books.

Eckert, C. M. \& Stacey, M. (2000) Sources of Inspiration: A Language of Design. Design Studies 21(5), 523538.

Feng, Z. (2015) Silks from the Silk Road: Origin, Transmission and Exchange China: Zhejiang university press. Kosslyn, S. M. (1980) Image and Mind. Cambridge, Massachusetts: Harvard University Press.

Lawson, B. (2006) How Designers Think: The Design Process Demystified, $4^{\text {th }}$ edition. Oxford: Elsevier/Architectural Press.

Lee, J. S. \& Jirousek, C. (2015) The development of design ideas in the early apparel design process: a pilot study. International Journal of Fashion Design, Technology and Education 8(2), 151-161.

Lurie, A. (1981) The Language of Clothes New York: Random House.

Mbonu, E. (2014) Fashion design research London: Laurence King Publishing Ltd.

Oxman (2002) The thinking eye: Visual re-cognition in design emergence. Design Studies 23(2), 135-164.

Pipes, A. (2003) Foundations of art and design. London: Laurence King.

Simmel, G. (1914) Philosophie der Mode. Berlin.

Solomon, M. R. (1985) The Psychology of Fashion Lexington, Massachusetts: Lexington Books.

Sproles, G. B. \& Burns, L. D. (1994) Changing Appearances: Understanding Dress in Contemporary Society New York: Fairchild Publications.

Volpintesta, L. (2014) The language of fashion design : 26 principles every fashion designer should know. Beverly: Rockport Publishers.

Watkins, S. M. (1988) Using the design process to teach functional apparel design. Clothing and Textiles Research Journal 7(1), 10-14. 